\title{
Middle East's Circular Economy Expectations for the Next Ten Years
}

\author{
Firas Al Kufy ${ }^{1 *}$ \\ ${ }^{1}$ Edmonton University, Australia \\ *Corresponding author: Firas Al Kufy: firassalih@gmail.com
}

\section{OPEN ACCESS}

Citation: Al Kufy F..(2021) Middle East's Circular Economy Expectations for the Next Ten Years. Open Science Journal 6(2)

Received: $13^{\text {th }}$ October 2020

Accepted: $11^{\text {th }}$ March 2021

Published: $26^{\text {th }}$ April 2021

Copyright: (C) 2021 This is an open access article under the terms of the Creative Commons Attribution License, which permits unrestricted use, distribution, and reproduction in any medium, provided the original author and source are credited.

Funding: The author(s) received no specific funding for this work

Competing Interests: The author has declared that no competing interests exists.

\begin{abstract}
:
This study provides an overview of waste management through circular economy in Middle East. Waste management has become a worldwide problem since humans are wasting resources as well as raw materials. This is the biggest problem faced by the humans on Earth that is getting attention of government representatives from all over the world. Recently, Middle East has also showed concerns regarding the amount of waste produced. Thus, several government representatives of Middle East have voiced their opinions and have taken an initiative to adopt this model. This article is based on the adoption of the model of circular economy in the countries of Middle East. This article explains the challenges that Middle East needs to be aware of for successful implementation of this model.
\end{abstract}

Keywords: Middle East, Model of Circular Economy, Waste Management

\section{Introduction}

Waste production has become a worldwide problem for humans since it is affecting them through every field. Moreover, it has also led to the generation as well as application of innovative measures to reduce waste production and to eliminate waste produced. People are forced to depend on such extensive measures since they are producing waste at an alarming rate on Earth. One of such innovative measures for elimination of waste produced is the circular economy, which will be discussed in this article.

This article introduces the model as well as application of circular economy as well as determines its benefits as well as usage on Middle East. Moreover, it also explains the need of circular economy in Middle East countries along with the application of circular economy in those countries. This article explains the expectations of Middle East countries in association with the application of circular economic model in the respective economies. Furthermore, this article 
also explains the challenges faced by the circular economy regarding its application in an economy.

\section{Understanding circular economy from theoretical perspectives}

\section{Concept of circular economy}

Through circular economy, activities of an economy are able to build as well as rebuild the overall health of the system. This model has been given importance since its usage will lead to the saving of huge amount of consumption of energy as well as resources. Moreover, the transition to circular economy leads to shifts in the system through which business, long-term resilience as well as economic opportunities are generated. This transition will also lead to the provision of social as well as environmental benefits along with reduction of ill effects of linear economy (Geissdoerfer et al. 2017).

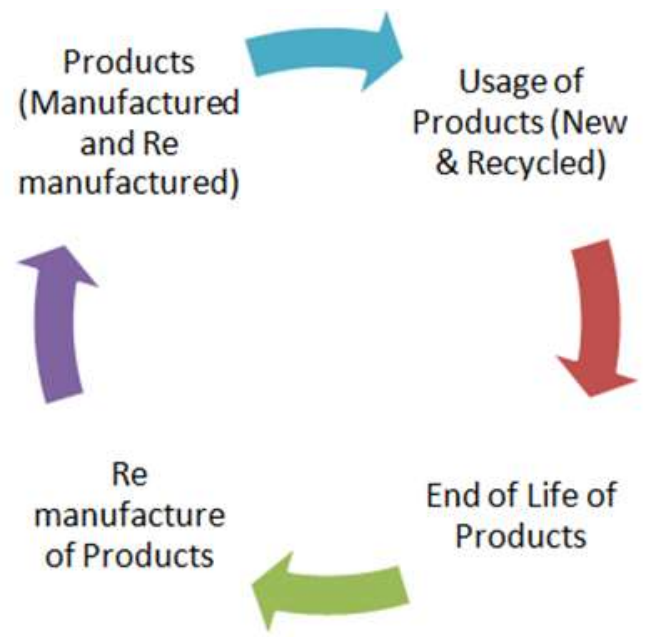

Figure 1: Model of circular economy

(Source: As influenced by Geissdoerfer et al. 2017)

\section{Distinguishing Circular Economy from Linear Model}

Moreover, the technical cycle and biological cycle are distinguished in this circular economy. Through biological cycles, only consumption happens via the processes such as anaerobic digestion as well as composting. Thus, the circular economic model opposes so-called linear model. In case of linear economy, output will be produced, then will be used as well as disposed. However, in the case of circular economy, the raw materials are used in such a way that a good's life cycle is reintegrated in production process. Using circular economy, a country will be able to recycle its goods, which it would otherwise dispose in linear economy. Thus, the circular economic model provides opportunities for conservation of resources as well as energy through which climate change can be prevented (Kirchherr et al. 2017). 


\section{Significance of circular economy}

Table 1: Needs for Circular Economy in an economy

\begin{tabular}{|c|c|}
\hline Needs & Explanation \\
\hline $\begin{array}{l}\text { Increase in Raw Material } \\
\text { Demand }\end{array}$ & $\begin{array}{l}\text { The demands for raw goods have been increasing throughout time. In the } \\
\text { past century, the overall population has been using too much raw } \\
\text { materials. Compared to the previous century, the demand for materials has } \\
\text { risen } 34 \text { times while for minerals } 27 \text { times and for fossil fuels } 12 \text { times. The } \\
\text { accelerated growth in the world population has also led to significant rise in } \\
\text { demand for materials. The environmental burden has risen while natural } \\
\text { resources have been continuously deteriorating (Government of the } \\
\text { Netherlands, 2019). }\end{array}$ \\
\hline $\begin{array}{l}\text { Dependent on the rest of the } \\
\text { World }\end{array}$ & $\begin{array}{l}\text { The model of circular economy is important since several economies are } \\
\text { dependent on the rest of the world for the raw materials. If the raw } \\
\text { materials can be recycled or reused, thousands of dollars will be saved for } \\
\text { the economy. The high usages of raw materials have made them scarce. } \\
\text { This will lead to the establishment of political tensions among several } \\
\text { countries. Rise in prices of raw goods will lead to the ill effects on economic } \\
\text { stability (Gaur et al. 2019). }\end{array}$ \\
\hline Climate Impact & $\begin{array}{l}\text { Another important factor for reduction in raw materials is that their } \\
\text { extraction as well as usage will lead to the increment in the consumption of } \\
\text { energy as well as } \mathrm{CO}_{2} \text { emissions (Government of the Netherlands, 2019). }\end{array}$ \\
\hline Economic Opportunities & 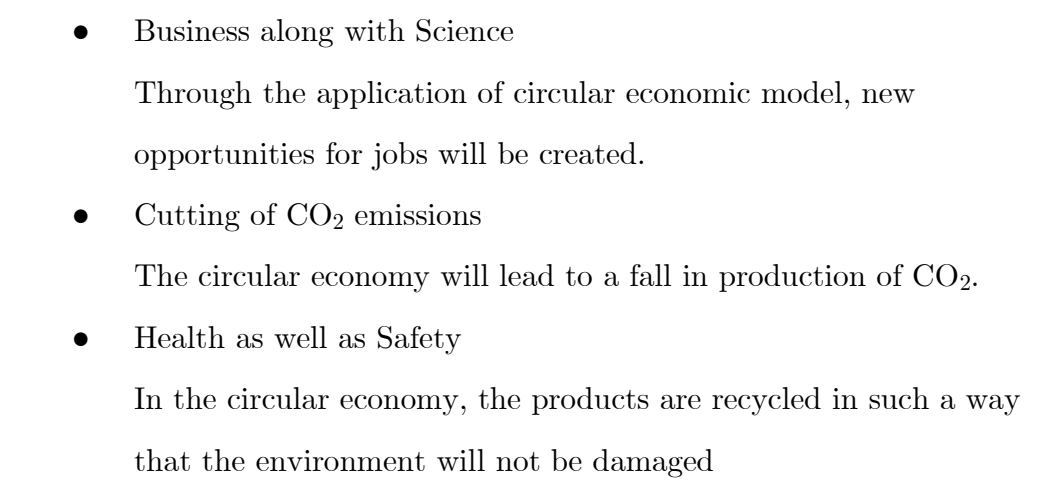 \\
\hline
\end{tabular}

(Source: Self-developed) 
Results arising out of the application of circular economy in the Middle East

Circular economy is gaining recognition throughout the world since it is an innovative idea to tackle the problem of huge amounts of waste produced all over the world. The application of PACE in an economy is hoped to accelerate the achievement measures towards the circular economy. This can be done through the driving of projects, disseminating as well as capturing learning along with leveraging of leadership. The goal of PACE is to expand the markets of Middle East and the rest of the world such that the circular economy can be applied. 55 billion dollars can be saved by using recycled products in the electronics sector. Moreover, PACE also stated that by the year 2050, more products that are plastic would be present in the ocean than fish. Using circular economy as stated by PACE, one-third of food can be saved through reuse or recycle (PACE, 2019). [Refer to Appendix 1]

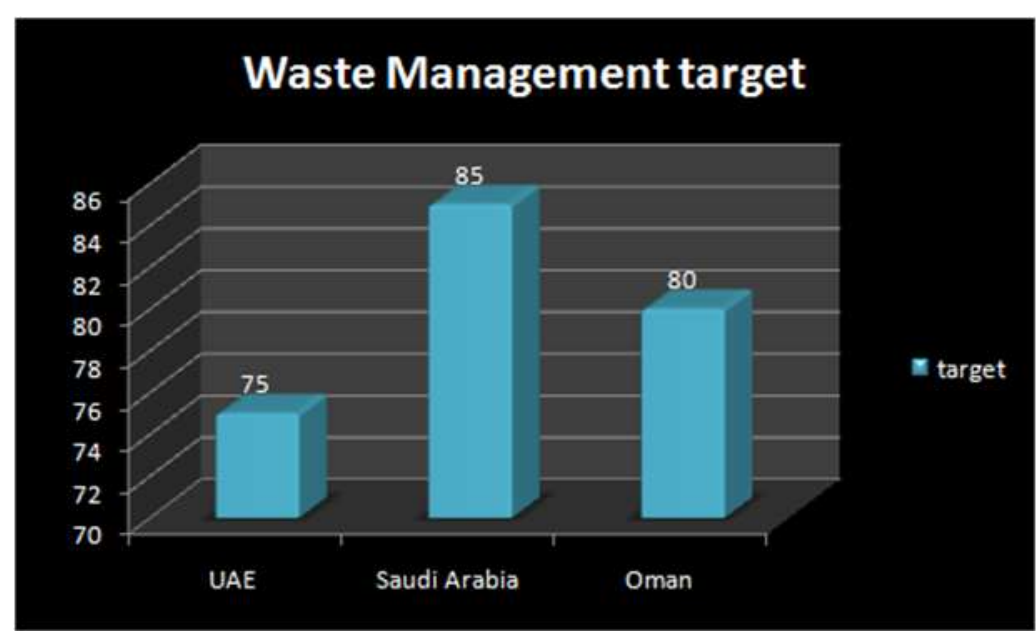

Figure 2: Target for Waste Management in UAE, Saudi Arabia and Oman (Source: Al-Sadoun, 2018)

\section{Approach of take-make-use-dispose}

The approach of take-make-use-dispose has been often used to recycle products, especially plastic ones. However, this takes a lot of energy as well as resources unlike circular economy. UAE produces the highest amount of waste per capita of $2.1 \mathrm{~kg}$ per day (Al-Sadoun, 2018). Saudi Arabia and Bahrain produces waste at $1.7 \mathrm{~kg}$ per capita each day while Kuwait at $1.5 \mathrm{~kg}$ and Oman at $1.2 \mathrm{~kg}$ (Al-Sadoun, 2018). The recycling along with waste treatment is also included in the visions of GCC. These visions determine that UAE aims for $75 \%$ of treatment of solid waste by 2021. Moreover, Saudi Arabia targets $85 \%$ while Oman targets $80 \%$ to be the recycling rate by 2030 (Al-Sadoun, 2018). [Refer to Appendix 2]

Understanding circular economy in the Middle East from economic perspective

If the Middle East countries are able to adopt the model of circular economy, they will be able to save nearly 138 billion dollars by 2030. This will increase the 
total GDP of Middle East economies by $1 \%$ approximately. The waste produced by the Middle East countries contributes nearly $35 \%$ to $40 \%$ compared to $25 \%$ to $30 \%$ in the EU (Arabian Business, 2019). These sectors of the Middle East are being targeted by GCC while incorporating the model of circular economy.

\section{Fluctuation in economic conditions in the Middle East}

The recession suffered by the Middle East economies in 2019 also led the economy to slow down. Thus, GDP of these economies reduced significantly. Oman's economy is expected to suffer from a weaker growth of approximately $2.8 \%$ in 2018 against the estimated growth of nearly 3.3\% (ICAEW, 2019). Moreover, Bahrain observed its economic growth to fall considerably from $3.7 \%$ to $1.8 \%$ in the year 2019. Thus, GCC also claims that incorporation of model of circular economy will also lead to the saving of GDP in the Middle East economies (ICAEW, 2019).

\section{Institutional efforts towards capitalization of circular economy}

A new coalition of UAE governments, private companies as well as NGOs have taken a pledge to save the Earth from the huge amount of waste produced on 22nd April, 2019 (Williams, 2019). The pledge included the introduction initiative of circular economy in the Middle East economies. The government of UAE has put 1 million dollars for the support of initiative. It uses Scale 360 that has the potential to reduce waste as well as recycle resources efficiently (Williams, 2019). If the chains of circular supply have been enabled in the Middle East economies for increasing the recycling, remanufacturing as well as reusing rate, nearly 0.1 million jobs will be created and 1 trillion dollars can be generated each year for the global economy up to 2025 (Williams, 2019).

\section{Waste management efforts realised via procedural approaches}

The usage of circular economic model gives incentives to use healthy materials that will lead to closed loop non-toxic systems as well as promotion of renewable energy. Middle East is now concerned with the climate change in its countries having tremendous impact on these changes. The leaders of the Middle East are trying to implement changes in the waste management procedures. The vision of UAE includes the targets on waste treatment, renewable energy development, air quality as well as water recycling (d'Escury, 2016).

\section{Fulfilling the need for skills}

UAE is working on the development of a project of solar energy that consists of nearly three hundred football pitches. Tianjin, a city in the Middle East has been predicted to have a GDP of nearly 625 billion dollars if the circular economy is adopted by China. For the successful inclusion of circular economic model in the Middle East, new skills need to be developed in the Middle East. Thus, the semi-skilled as well as the highly skilled are needed to support the model on circular economy leading to the generation of opportunities for jobs in the Middle East. The industries of recycling as well as remanufacturing account for over 1,000,000 jobs (d'Escury, 2016). 




Figure 3: Consequences of Circular Economy

(Source: World Future Energy Summit, 2019)

\section{Introduction of model pertaining to circular economy}

Through Scale 360, the UAE has taken an innovative initiative to introduce the model on circular economy in its country. This model having closed loop will be able to stop nearly 13,000,000 tonnes plastic from polluting the oceans in the world. Moreover, Saudi Arabia announced the initiative of recycling as well as usage of plastic products in the production facilities. Through the acceptance of circular economy, landfill can be reduced by 2,000,000 tonnes each year. This will save approximately 1,500,000 tonnes of carbon dioxide from being emitted leading to the generation of 50 million dollars (World Future Energy Summit, 2019).

\section{Procurement of PPP}

The circular economy has been found to be beneficial for the economies in the Middle East. The countries in the Middle East have gained an inclination for the procurement of PPP. This has been due to the application of PPP procurements in the rest of the world. Moreover, PPP model can be applied in the economy if the private sector is able to include innovation in a project. This will lead to the creation of synergies in association with the model of a circular economy. The economies in the Middle East have PPP procurements in the economy. This will make it easier for the application of circular economy in the Middle East since the procedure of applying PPP will be the base of circular economy. Thus, the introduction of PPPs in waste management has made it easier for the Middle East economies to introduce circular economy (Taqi, 2017).

\section{Challenges of Circular Economy}

Though the setup of circular economy is an excellent idea, it faces several challenges in its application in the economy. These challenges faced through the setup of circular economy are: 


\section{Efficient Control of life cycles}

Due to the presence of several products that are hard to recycle, product designers have no incentive to bring end-of-life considerations in their respective products. The application of the circular economy will need the integration of life cycle of product done through intensive collaboration. Since companies own entire product life cycle, this becomes a challenging task to the incorporation of circular economy (Korhonen et al. 2018).
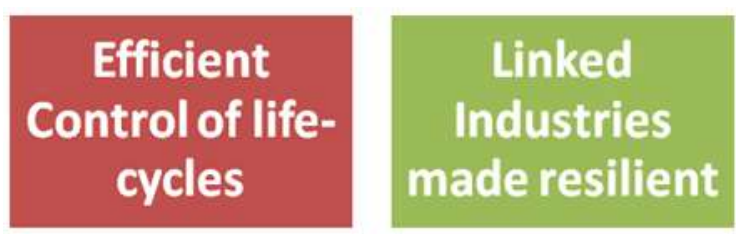

\section{Focusing on \\ the \\ Environment}

Figure 4: Challenges of Circular Economy

(Source: Korhonen et al. 2018)

\section{Linked industries made resilient}

It is often found that an economy cannot incorporate circular economy due to the presence of a single industry that cannot follow closed loops. This is because of the presence of several collapses as well as complexities. Moreover, a series of events may lead to the crashing of the system in the economy.

\section{Focusing on the environment}

The integration of life cycles as well as industries may induce the establishment of complex systems hampering competition and making the economy vulnerable. In other words, the complex systems may hamper the growth of the economy and may lead to a reduction in the national income of the economy.

\section{Conclusion}

The article explains the circular economy and determines the scope of this model on the Middle East economies. This article has determined that the Middle East countries have accepted the idea of circular economy in the world. The governments of Middle East countries are trying to incorporate the circular economy within their countries. Application of circular economy has also many benefits to the country. The circular economy will make the Middle East countries healthier and richer through its application in the waste management in the coming ten years. It has been determined in the article that the circular economy will lead a particular economy from the waste of products to the recycling of products. However, the challenges for circular economic model are 
also present that needs to be considered. Thus, though the circular economy has several benefits, the government must be aware of the barriers to overcome them.

\section{References:}

Al-Sadoun, A., (2018). Opinion: Enabling a circular economy in the Arabian Gulf. Refining and Petrochemicals. Available from https://www.refiningandpetrochemicalsme.com/productsservices/24373-opinion-enabling-a-circular-economy-in-the-arabian-gulf [Accessed on 09/08/2019]

Arabian Business, (2019). How a circular economy could save the GCC $\$ 138$ bn by 2030 . Available from https://www.arabianbusiness.com/politics-economics/413126-how-circular-economy-couldsave-the-gcc-138bn-by-2030 [Accessed on 09/08/2019]

d'Escury, A., C., (2016). Circular Economics: Generating Jobs for the Young in the Middle East and Africa. HuffPost. Available from https://www.huffpost.com/entry/circular-economics-generatingjobs_b_7432780 [Accessed on 09/08/2019]

Gaur, J., Mani, V., Banerjee, P., Amini, M. and Gupta, R., (2019). Towards building circular economy: a cross-cultural study of consumers' purchase intentions for reconstructed products. Management Decision, 57(4), pp.886-903.

Geissdoerfer, M., Savaget, P., Bocken, N.M. and Hultink, E.J., (2017). The Circular Economy-A new sustainability paradigm?. Journal of cleaner production, 143, pp.757-768.

Government of Netherlands, (2019). The need for a circular economy. Available from https://www.government.nl/topics/circular-economy/the-need-for-a-circular-economy [Accessed on $09 / 08 / 2019]$

ICAEW, (2019). Economic Update: Middle East. Available from https://www.icaew.com/technical/economy/economic-insight/economic-insight-middle-east [Accessed on 09/08/2019]

Kirchherr, J., Reike, D. and Hekkert, M., (2017). Conceptualizing the circular economy: An analysis of 114 definitions. Resources, Conservation and Recycling, 127, pp.221-232.

Korhonen, J., Honkasalo, A. and Seppälä, J., (2018). Circular economy: the concept and its limitations. Ecological economics, 143, pp.37-46.

PACE, (2019). Public Overview. Available from https://static1.squarespace.com/static/5c3f456fa2772cd16721224a/t/5c485ee140ec9a50cd1e0c2e/1 548246766602/PACE + Public + Overview.pdf [Accessed on 09/08/2019]

Taqi, J., E., (2017). Sustainable Cities: PPPs and the emergence of the circular economy in the Middle East. Norton Rose Fulbright. Available from https://www.nortonrosefulbright.com/en/knowledge/publications/ab20952f/sustainable-citiesppps-and-the-emergence-of-the-circular-economy-in-the-middle-east [Accessed on 09/08/2019]

Williams, D., (2019). UAE Signs on to Circular Economy Plan. Chemanager-Online. Available from https://www.chemanager-online.com/en/news-opinions/headlines/uae-signs-circular-economy-plan [Accessed on 09/08/2019]

World Future Energy Summit, (2019). Embracing the circular economy: new ME and global initiatives. Available from https://www.worldfutureenergysummit.com/wfes-insights/embracingthe-circular-economy-new-me-and-global-initiatives\#/ [Accessed on 09/08/2019] 


\section{Appendices}

Appendix 1: Activities of PACE

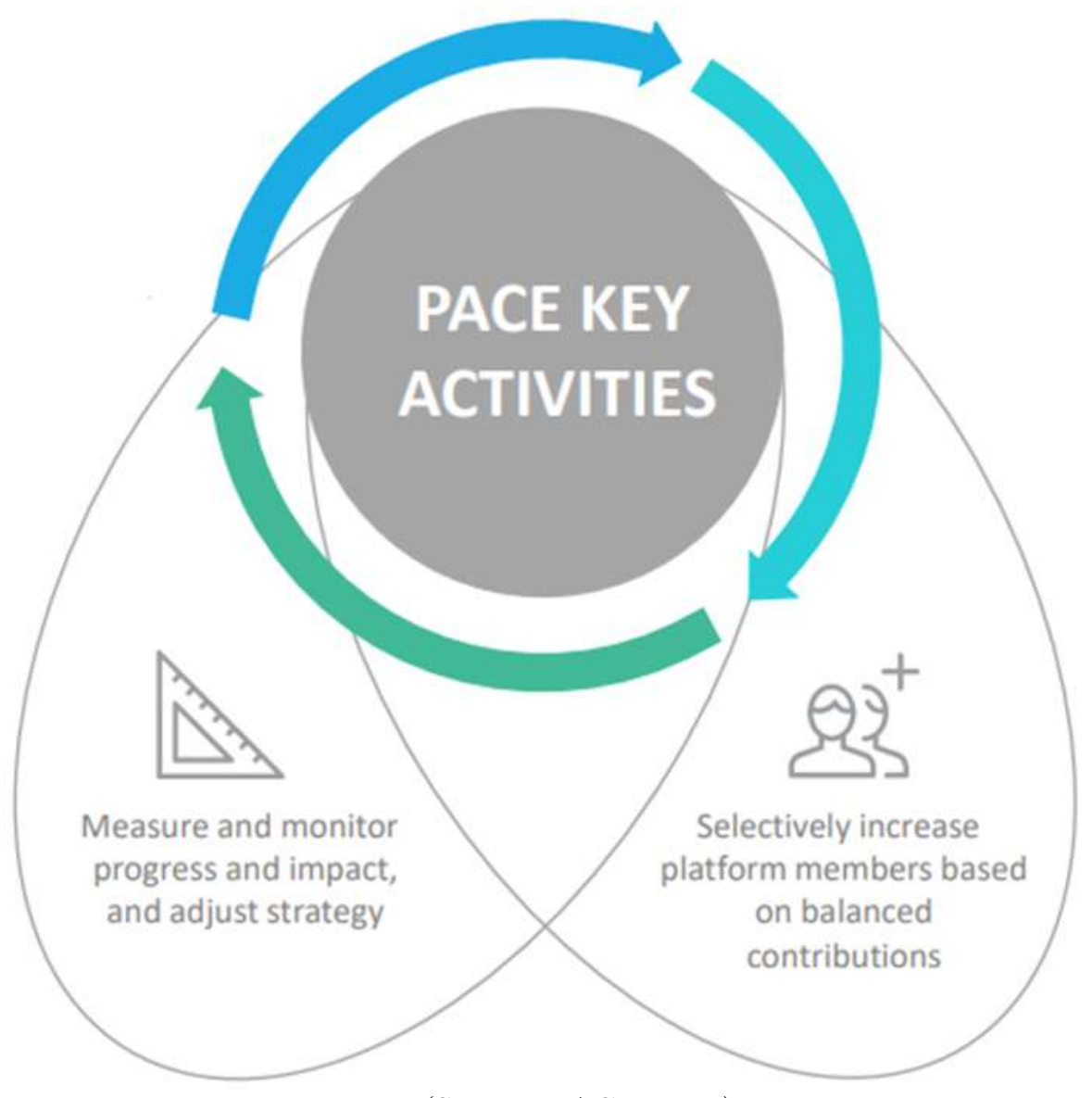

(Source: PACE, 2019) 
Appendix 2: Recycling process of plastic in circular economy

\section{Plastics in the circular economy}

Only $14 \%$ of plastic

pockooing is rocychd, with USD

$80-120$ billion phatie velwo bet bo the ecorromy

Berter product detim cin san up: USD 140 lor wach wen of phaste waib coloctod

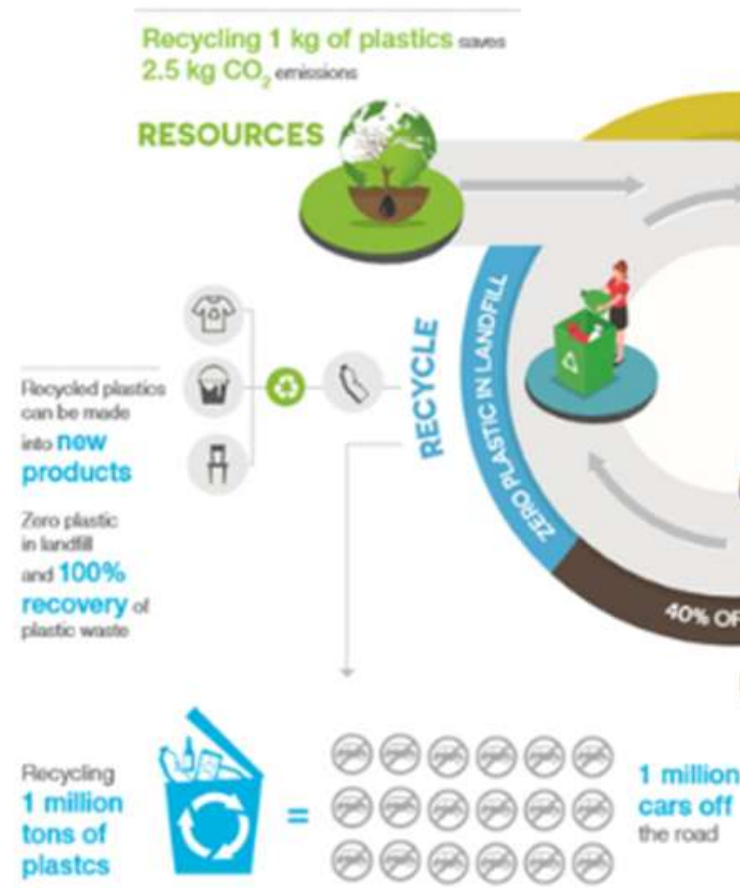

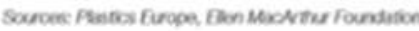

(Source: Al-Sadoun, 2018) 